\title{
ANÁLISE DA RETENÇÃO NO ENSINO SUPERIOR: UM ESTUDO DE CASO EM UM CURSO DE SISTEMAS DE INFORMAÇÃO
}

\author{
Léo Manoel Lopes da Silva Garcia ${ }^{1}$ \\ https://orcid.org/0000-0003-4861-8830 \\ Daiany Francisca Lara ${ }^{2}$ \\ https://orcid.org/0000-0002-0458-9196 \\ Franciano Antunes ${ }^{3}$ \\ https://orcid.org/0000-0003-1839-3300
}

RESUMO: Os altos índices de evasão e retenção no ensino superior a algum tempo é de conhecimento comum, principalmente no que tange aos cursos de ciências exatas e tecnologia. Mesmo antes dos estudos mostrarem dados sobre este tema, a experiência docente já estava familiarizada com esse fenômeno. No entanto, tais estudos realizam um relevante papel subsidiando aos gestores com informações que os auxiliem na elaboração de planos de ações ao combate à retenção. Enquanto a evasão possui diversas definições que se tornam similares em sua interpretação, a retenção tem um entendimento discrepante a cada estudo, o que se reflete na maneira de analisá-la. Este estudo propõe a utilização uma matriz de análise da retenção que contempla diversas e possíveis situações pelas quais um aluno possa ser retido em uma disciplina e possibilite uma melhor compreensão do fenômeno, utilizando um curso de Sistemas de Informação de uma instituição pública como estudo de caso.

PALAVRAS CHAVE: retenção, permanência, desempenho acadêmico, reprovação, evasão.

\section{RETENTION ANALYSIS IN HIGHER EDUCATION: A CASE STUDY IN AN INFORMATION SYSTEMS}

ABSTRACT: The high rates of dropout and retention in tertiary education for some

\footnotetext{
${ }^{1}$ Mestre em Ciências da Computação. Docente na Universidade do Estado de Mato Grosso. Barra do Bugres -MT, Brasil.leoneto@unemat.br

${ }^{2}$ Mestre em Informática. Docente na Universidade do Estado de Mato Grosso. Barra do Bugres - MT, Brasil. dflara@unemat.br

${ }^{3}$ Mestre em Ciências da Computação. Docente na Universidade do Estado de Mato Grosso. Cáceres - MT, Brasil.franciano@unemat.br
}

Rev. Fac. Educ. (Univ. do Estado de Mato Grosso), Vol. 34, Ano 19, № 2, p. 15-38, jul/dez., 2020 (Epub Ahead of Print 20 set., 2020) 
time is common knowledge, especially as regards the courses of exact sciences and technology. Even before the studies showed data on this subject, the teaching experience was already familiar with this phenomenon. However, such studies play an important role by subsidizing managers with information that may assist in the elaboration of plans and actions to combat evasion and retention. While the evasion has different definitions that become similar in its interpretation, the retention has a discrepant understanding to each study, which is reflected in the way of analyzing it. This study proposes the use of a retention analysis matrix that contemplates several possible situations by which a student may be retained in the discipline and allows a better understanding of the phenomenon, using an Information Systems course from a public institution as a case study.

KEYWORDS: retention, permanence, academic performance, disapproval, evasion.

\section{ANÁLISIS DE RETENCIÓN EN LA EDUCACIÓN SUPERIOR: UN ESTUDIO DE CASO EN UN CURSO DE SISTEMAS DE INFORMACIÓN}

RESUMEN: Las altas tasas de deserción y retención en la educación superior han sido de conocimiento común durante algún tiempo, especialmente con respecto a los cursos exactos de ciencias y tecnología. Incluso antes de que los estudios mostraran datos sobre este tema, la experiencia docente ya estaba familiarizada con este fenómeno. Sin embargo, tales estudios juegan un papel relevante al proporcionar a los gerentes información que puede ayudar en la elaboración de planes y acciones para combatir la evasión y la retención. Si bien el abandono tiene diferentes definiciones que se vuelven similares en su interpretación, la retención tiene una comprensión discrepante para cada estudio, lo que se refleja en la forma en que se analiza. Este estudio propone el uso de una matriz de análisis de retención que contempla varias situaciones posibles por las cuales un estudiante puede ser retenido en la disciplina y permite una mejor comprensión del fenómeno, utilizando un curso de Sistemas de Información de una institución pública como estudio de caso.

PALABRAS CLAVE: retención, permanencia, rendimiento académico, fracaso, deserción.

\section{Introdução}

O ensino superior é, em qualquer sociedade moderna, um dos motores do desenvolvimento econômico, sendo, igualmente, o instrumento principal de transmissão da experiência cultural e científica acumulada pela humanidade (FERREIRA, 2009). Dado o papel desempenhado pelas instituições de ensino na 
área tecnológica e científica da sociedade atual, o interesse pelo tema sucesso acadêmico na universidade tem gerado diversas pesquisas visando identificar quais fatores poderiam prever este sucesso (PARKER, 2004).

Pode-se entender como sucesso ao acadêmico quando a universidade cumpre o papel de fornecer profissionais capacitados para a sociedade e para o mercado de trabalho, e os casos contrários a isso podem ser entendidos como insucesso. Sob este parâmetro de insucesso, figuram-se os fenômenos da evasão e da retenção no ensino superior, pois retardam e reduzem drasticamente o número de concluintes de cursos superiores. Embora suas causas não sejam muito bem compreendidas, possuem efeitos danosos bem perceptíveis, principalmente para a sociedade, tais como: desperdício de capacidade voltada à formação e capacitação; menor eficiência produtiva das empresas; perda de competitividade nacional; carência de mão-de-obra especializada, entre outros fatores (SILVA, 2007). Em um grande número de estudos, tanto nacionais quanto internacionais, a retenção tem papel secundário, tendo em vista que a maior parte tem como foco a evasão (PEREIRA, 2016), muitas vezes, estes problemas são abordados como fenômenos similares ou como causa um do outro.

Mesmo estando em um aspecto secundário na maioria dos estudos, a retenção também apresenta seus impactos negativos à sociedade, ao não permitir que profissionais de nível superior venham a atuar em suas respectivas áreas do conhecimento no prazo inicialmente previsto. Ademais, os alunos retidos podem, em algum momento, evadir-se (CAMPELLO, 2008). No trabaIho de Yamaguchi (2019), é identificado na instituição do estudo que o risco de atraso à diplomação aos alunos com 1 reprovação é de 2,3 vezes maior ao daqueles sem nenhuma reprovação, alunos com duas a cinco reprovações, o risco é de 4,8 vezes, e já para aqueles com mais de 5 reprovações, o risco é de 41,7 vezes. É evidenciado, então, que a reprovação nessa instituição possui efeito exponencial na permanência prolongada nos cursos, e pode-se inferir que a falta de expectativa de se formar, pode gerar desânimo nos alunos e provocar a evasão definitiva do curso.

Reconhecido esta problemática, antes de considerar o planejamento e execução de práticas que combatam a retenção, é necessário realizar um diagnóstico em cada disciplina em particular acerca do índice de reprovação. No entanto, a simples informação da quantidade ou percentual de retenção em uma disciplina pode não ser o suficiente, podendo inclusive levar a interpretações errôneas sobre a situação de uma disciplina. Considerando as diversas modalidades de aprovação e reprovação (dependendo da normatização 
acadêmica de cada instituição), é preciso observar em cada oferta qual o tipo de reprovação que cada aluno se enquadra, para só então identificar qual é o tipo de problema a ser enfrentado.

Dessa maneira, o presente estudo propõe utilizar uma metodologia de análise da retenção que contemple todas as situações possíveis para aprovação e reprovação em uma disciplina, para tanto a metodologia foi aplicada em um curso de Sistemas de Informação de uma instituição pública, abordando a retenção por disciplina, fase do curso, semestre letivo e no curso como um todo. Foi analisado o período acadêmico de 2014/2 a 2019/1, com base em dados dos diários eletrônicos de cada disciplina inseridos no sistema acadêmico da instituição.

\section{Estudos sobre retenção no ensino superior}

No Brasil, tanto os estudos sobre evasão quanto os estudos sobre retenção no ensino superior, têm seu marco histórico na criação da Comissão Especial de Estudos sobre a Evasão nas Universidades Públicas Brasileiras (CEESE, 1996), cujo objetivo foi compreender com profundidade o tema evasão, retenção e diplomação e, posteriormente, contribuir para que as Instituições Federais de Ensino Superior reduzam sua taxa de evasão. Como fruto desta comissão foi gerado um documento reunindo um conjunto de dados sobre o desempenho das universidades públicas brasileiras em relação aos índices de diplomação, retenção e evasão dos estudantes de seus cursos de graduação (MEC, 1997).

Neste documento, a comissão define retenção como o caso em que o aluno já esgotou o prazo máximo de integralização previsto para o curso e ele ainda não o concluiu. Já em (CESARINO, 1987 apud VANZ, 2016) é entendido que a retenção se refere ao aluno que, por qualquer motivo, não terminou ou não teria condição de terminar o curso de graduação no tempo mínimo previsto pelo currículo padrão. Lammers (2017) também relaciona em seu estudo a retenção como a permanência no curso a mais do prazo mínimo estabelecido e apresenta o conceito de reprovação como causa da retenção. Tal é a discrepância na adoção do conceito de retenção que em alguns trabalhos é apresentando como algo positivo, como em Assis (2013), onde o autor descreve como retido, o aluno que não se evade do curso. E divergindo das abordagens anteriores Lautert (2011) e Rissi (2013) abordam a retenção na disciplina contemplando os casos de não obtenção de nota suficiente para aprovação, ou de frequência insuficiente. Esta será a abordagem utilizada nesse estudo, dessa 
maneira, será tratado a retenção como a reprovação em uma disciplina por quaisquer dos motivos previstos na normatização acadêmica da instituição.

\section{Trabalhos Correlatos}

Muitos trabalhos desenvolvidos em relação a retenção no ensino superior são correlatos ao presente estudo, em Campello (2008), é realizado um modelo de agrupamento de alunos em clusters a partir de dados do curso de graduação em Engenharia de Produção, método pelo qual os alunos foram agrupados de acordo com seu desempenho acadêmico baseado nas notas, reprovação, trancamento e matrículas, para posterior busca de evidências das causas de evasão ou retenção, um total de 6 perfis foram estabelecidos, cada qual com um comportamento particular quanto a retenção e a evasão. Também utilizando um curso de Engenharia como campo de estudo, Rios (2001) avalia as reprovações durante o ciclo básico do curso contemplando as disciplinas de Matemática, Física e Química, nas quais constatou-se que o desempenho foi medido em relação às pontuações obtidas nas disciplinas, e foi confrontado também com as notas obtidas no vestibular nessas mesmas disciplinas básicas. Como resultado foi evidenciado uma melhoria em relação ao desempenho do vestibular, e concluído pelos autores que a falta de base com que os alunos chegam a instituição como um dos principais aspectos determinantes das reprovações e evasões nos cursos de Engenharia da Instituição.

Com uma motivação similar aos cursos de Engenharia, em cursos de Sistemas de Informação, e outros da área de tecnologia, os estudos comumente abordam as disciplinas com maior ênfase de reprovação, geralmente, na área de programação e, ocasionalmente, Cálculo e outras disciplinas ligadas à Matemática. Em Bosse (2015), é realizado um levantamento quantitativo das disciplinas de introdução a programação na Universidade de São Paulo, cujo resultados apresentaram um índice de reprovação de $29 \%$ no geral, e uma incrível variação de $5,8 \%$ a $68 \%$ ao se analisar individualmente cada oferta de disciplina. Neste trabalho todas as disciplinas de programação foram consideradas, inclusive quando ofertadas em cursos fora da área de tecnologia. Porém, é apropriado observar a importância deste grupo de disciplinas, como fundamentais ao currículo dos cursos de tecnologia, nos quais o baixo desempenho ou reprovação pode comprometer o desempenho nas demais disciplinas do curso, gerar frustração e provocar a evasão do acadêmico.

A Universidade Federal do Espirito Santos (UFES), em seu caderno de avaliação do curso de Sistemas de Informação (CADERNO DE AVALIAÇÃO 
UFES, 2013), apresenta a avaliação institucional do referido curso, e, em seu conteúdo acrescenta os índices de reprovação obtidos por cada disciplina nos semestres analisados, neste documento é demonstrado ainda o desempenho por alunos ingressos pelo sistema de cotas, no qual verificou-se que há oscilação de desempenho entre cotistas e não cotistas para o curso de Sistemas de Informação, porém as diferenças foram mais explícitas quando a comparação foi realizada em outros cursos da instituição. Semelhante a este trabalho a Universidade Estadual de Londrina (UEL), publicou em 2011 um Estudo sobre a Reprovação e Retenção nos Cursos de Graduação (RISSE, 2011) e em 2013 a Reflexão sobre a reprovação, retenção e evasão na UEL: retenção em 2010, reprovação 2010 a 2012 e evasão 2003 a 2012 nos cursos de graduação (RISSE, 2013). Ambos os trabalhos apresentam um levantamento estatístico considerando somente o percentual total de reprovação de cada disciplina.

\section{Proposta de Pesquisa}

Este estudo realiza um levantamento sobre a retenção em um curso de Sistemas de Informação da Universidade do Estado de Mato Grosso - UNEMAT no campus de Colíder. O período eletivo investigado é de 2014/2 a 2019/1, a pesquisa é realizada através de análise documental, tendo acesso ao sistema acadêmico da instituição e por ele o diário eletrônico de todas as disciplinas ofertadas no período. Considerando os trabalhos correlatos e demais referenciais bibliográficos, um dos objetivos aqui pretendidos é desenvolver uma matriz de análise que possibilite uma visualização multifacetada da ocorrência da retenção nas disciplinas para que subsidiar aos gestores e aos pesquisadores no sentido de se obter um melhor entendimento sobre este fenômeno.

\section{Coleta de Dados e Resultados}

Antes de se realizar a coleta e processamento dos dados foi necessário definir a compreensão de retenção a ser admitida, será aqui considerado como retenção a condição em que o aluno não seja aprovado em uma disciplina, ou seja, quando ele fracassa em todas as possibilidades ofertadas para sua aprovação, como média insuficiente durante as avaliações do semestre, ou nota suficiente no exame final, não eximindo também suas responsabilidades em relação a frequência mínima na disciplina.

Nesta fase, o desenvolvimento e a definição da matriz de análise foram realizados. É proposta uma categorização dos casos de retenção, com- 
preendendo que apenas a quantificação do número de retidos (quantidade de reprovados) em uma disciplina ou curso não representa informações suficientes para subsidiar o diagnóstico, planos e ações para o combate a retenção em um curso ou disciplina. A categorização foi baseada nas normativas acadêmicas da universidade, e foram elencados 3 casos possíveis de retenção na disciplina, são eles: reprovado por falta, quando o aluno atinge uma frequência de presenças inferior a $75 \%$ da carga horária da disciplina; reprovado direto por nota quando obtém uma média final da disciplina inferior a 5,00 pontos (média insuficiente para exame final) e reprovados na prova final quando o aluno obtém nota inferior a 5,00 no exame final (para ter desempenho suficiente para a prova final quando ele obtém como média final da disciplina um valor entre 5,00 e 7,00 pontos). Os casos de aprovação também foram categorizados em aprovação direta quando o aluno obtém média igual ou superior a 7,00 pontos e aprovado na prova final quando ele obtém a média igual ou superior a 5,00 no exame final.

Uma abordagem utilizada exclusivamente por esse estudo foi a quantificação da retenção sob dois aspectos, a retenção absoluta e retenção líquida, a utilização destes aspectos foi motivada pela observação dos relatórios fornecidos pelo sistema acadêmico da instituição (semelhante a outros sistemas acadêmicos de demais instituições de ensino superior), que exibe o total de aprovados e reprovados em uma disciplina junto com a taxa de reprovação. Normalmente, as taxas de reprovação são muito altas, $80 \%$ em alguns casos, no entanto, ao confrontar o professor da disciplina sobre este número, era informado que, dos alunos que realmente frequentaram as disciplinas, apenas $10 \%$ ou $20 \%$ reprovaram, os demais estavam na lista de alunos matriculados, mas nunca apareceram nas aulas ou apareceram algumas vezes no início. Dessa maneira, foi considerado como retenção absoluta todos os alunos matriculados na disciplina e que não foram aprovados e, retenção líquida, é baseada na retenção apenas dos alunos que possuíram no mínimo $50 \%$ de frequência nas disciplinas, considerando a frequência abaixo dessa marca como abandono da disciplina. A condição de abandono na disciplina foi implementada nesse estudo, com a compreensão que, os dados levantados poderão influenciar as ações da gestão e principalmente dos planos de ensino dos docentes, que podem buscar estratégias para evitar a retenção demasiada em sua disciplina (quando houver), no entanto, quando um aluno não possui uma mínima frequência (abaixo de 50\%) em uma disciplina, este aluno estará fora do alcance dos esforços do docente para obter êxito no processo de ensino e aprendizagem. Este abandono pode estar mais relacionado com a evasão do 
curso do que com a retenção da disciplina.

Uma vez decidido os aspectos a serem abordados, um instrumento de coleta de dados foi desenvolvido, baseado nas regras e orientações descritas nos parágrafos anteriores. O universo de amostra compreendeu os semestres letivos de 2014/2 a 2019/1 do curso analisado, acompanhando três turmas de ingressantes dos semestres 2014/2, 2015/1 e 2015/2, contemplando o ciclo completo de 8 semestres para cada turma. Ao total foram analisados diários eletrônicos de 138 ofertas de disciplinas, sendo 49 disciplinas distintas, as disciplinas bases da matriz foram ofertadas 3 vezes cada uma e as eletivas entre 1 a 3 ofertas.

Para cada oferta de disciplina, a matriz foi aplicada utilizando-se os dados dos diários eletrônicos disponíveis no sistema acadêmico, a Tabela 1 apresenta os dados da oferta da disciplina de Fundamentos de Sistemas de Informação no semestre letivo de 2014/2, turma de 2014/2.

Na Tabela 1, o item Frequentadores corresponde a quantidade de alunos que tiveram $50 \%$ ou mais de frequência na disciplina, sobre eles foi calculado a retenção líquida, que nesta disciplina foi de $13,33 \%$, enquanto a retenção absoluta foi de $44 \%$, o que demonstra a disparidade entra a retenção absoluta total e a retenção entre frequentadores. $O$ item abandono corresponde a todos alunos que possuíram frequência inferior a $50 \%$. Como pode ser observado os dados foram compilados, criando-se diversas categorias. Tem-se, por exemplo, o item reprovado por notas, que considera os alunos que não reprovaram por faltas, mas obtiveram reprovação direta ou reprovação na prova final, há também a informação sobre a quantidade em exame final, que não é uma reprovação em si, mas pode descrever uma dinâmica relevante para alguns professores ou gestores.

Tabela 1. Disc.: Fundamentos de Sistemas de Informação - Oferta 2014/2 - Turma 2014/2

\begin{tabular}{cc} 
Item de Análise & Quantidade \\
\hline Matriculados & 48,00 \\
\hline Quantidade Frequentadores & 30,00 \\
\hline Aprovados & 26,00 \\
\hline Retenção Absoluta & 22,00 \\
\hline Retenção Líquida & 4,00 \\
\hline Reprovados por Faltas & 19,00 \\
\hline
\end{tabular}




\begin{tabular}{cc}
\hline Reprovados Direto por Nota & 2,00 \\
\hline Reprovados por Nota & 3,00 \\
\hline Exame Final & 4,00 \\
\hline Aprovados Direto & 23,00 \\
\hline Aprovados Exame Final & 3,00 \\
\hline Reprovados Exame Final & 1,00 \\
\hline Média de Notas Geral & 4,14 \\
\hline Média de Notas Frequentadores & 6,63 \\
\hline Cancelado & 0,00 \\
\hline Abandono & 18,00 \\
\hline Média Frequência - Frequentadores & $92 \%$ \\
\hline Média Frequência - Geral & $59 \%$ \\
\hline
\end{tabular}

Fonte: Elaborada pelos autores.

Outra situação encontrada foi a de cancelamento, nesta situação o aluno retirou explicitamente a matrícula da disciplina em questão, o que também pode representar o trancamento do curso. Por fim, tem-se a média dos alunos frequentadores e a média geral dos alunos (todos alunos, inclusive os que abandonaram a disciplina), com estes dados é possível avaliar o desempenho dos alunos nas disciplinas, da mesma maneira apresenta-se os dados sobre a frequência média na disciplina tanto para frequentadores quanto para todos os alunos matriculados, onde pode ser analisado como anda a frequência ou a falta dela em cada disciplina.

As categorizações da retenção e da aprovação, foram cruciais na metodologia do trabalho, as quais possibilitaram um diferencial na apresentação de resultados. Somente o percentual total absoluto de reprovação da disciplina caracteriza-se como informação incipiente, que pode não fornecer critério para interpretação alguma ou pode inferir uma interpretação errônea. A Imagem 1, demonstra como é fornecido o relatório de reprovações, pelo sistema acadêmico da instituição. Esta forma de relatório é similar a utilizada por Rissi (2011) e Rissi (2013), (poderia dizer que são idênticas, não fosse as particularidades de layout dos sistemas acadêmicos de cada instituição).

Como poder ser visto na Imagem 1, é fornecido somente o percentual total de reprovados, mas os dados da Tabela 1, assim como todos os dados que forem apresentados, confirmam a hipótese que há uma grande diferença 
entre o total de reprovados (retenção absoluta $=22$ ) e aqueles alunos que realmente frequentaram a disciplina e falharam e consequentemente reprovaram (retenção líquida $=4$ ). É sobre essa falha que os professores podem atuar proporcionando diferentes estratégias de ensino, de recursos, avaliação de aprendizagem, entre outros elementos didáticos e de mediação.

\section{Imagem 1: Relatório de Reprovações.}

\begin{tabular}{|c|c|c|c|c|c|c|c|}
\hline \multirow[b]{2}{*}{$\begin{array}{l}\text { cord_oferecid } \\
\text { a }\end{array}$} & \multicolumn{3}{|c|}{$\begin{array}{l}\text { Instituiçăa: UNIVER SIDADE DO ESTADO DE MATO GROSSO } \\
\text { Relatório: Número de aprovados e reprovados por curso no periodo } \\
\text { Emitido: 03/03/2017 21:59 (01308667175) }\end{array}$} & \multirow[b]{2}{*}{$\begin{array}{l}\text { num_m } \\
\text { atricula } \\
\text { dos. }\end{array}$} & \multirow[b]{2}{*}{$\begin{array}{l}\text { num_ap } \\
\text { rovadao } \\
\mathbf{s}\end{array}$} & \multirow[b]{2}{*}{$\begin{array}{l}\text { num_re } \\
\text { provadi } \\
\text { os }\end{array}$} & \multirow[b]{2}{*}{ per_reprovados } \\
\hline & cod_curso & periodo & disciplina & & & & \\
\hline$\overline{180061}$ & COL60 & $2015 / 1$ & ALGORITMO I & $\frac{005}{23}$ & $\frac{s}{11}$ & $\frac{\cos }{12}$ & 52,17 \\
\hline 179996 & COL60 & $2015 / 1$ & FUNDAMENTOS DA MATEMÄTICA ELEMENTAR (NIVELAMENTO) & 45 & 36 & 9 & 20,00 \\
\hline 179979 & COL60 & $2015 / 1$ & FUNDAMENTOS DE SISTEMAS DE INFORMAÇĀ̄O & 46 & 34 & 12 & 26.09 \\
\hline 179999 & COL60 & $2015 / 1$ & GEOMETRIA ANALIITICA & 34 & 21 & 13 & 38,24 \\
\hline 180062 & COLGO & $2015 / 1$ & INTRODUÇÃO A COMPUTAÇ:ÃO & 45 & 36 & 9 & 20,00 \\
\hline 180066 & COLGO & $2015 / 1$ & INTRODUÇÃO A METODOLOGIA CIENTIIFICA & 23 & 16 & 7 & 30,43 \\
\hline 179985 & COL60 & $2015 / 1$ & LINGGUA PORTUGUESA (NIVELAMENTO) & 46 & 34 & 12 & 26.09 \\
\hline 179990 & COLEO & $2015 / 1$ & LÓGICA & 46 & 34 & 12 & 26,09 \\
\hline 179991 & COL60 & $2015 / 1$ & MATEMÁTICA DISCRETA & 35 & 28 & 7 & 20,00 \\
\hline 17998: & COL60 & $2015 / 1$ & PRODUÇÄIO DE TEXTO E LEITURAA & 21 & 14 & 7 & 33,33 \\
\hline 180065 & COL60 & $2015 / 1$ & PSICOLOGIA APLICADA A SISTEMAS IDE INFORMAC,ĀOO & 44 & 36 & 8 & 18.18 \\
\hline 180190 & COLEO & $2015 / 1$ & TEORIA GERAL DA ADMIINISTRAÇ,̃̃O & 34 & 22 & 12 & 35,29 \\
\hline
\end{tabular}

Fonte: Recorte do sistema acadêmico SAGU.

Quanto ao percentual de alunos que abandonam a disciplina (fora do alcance dos recursos didáticos do professor), deve ser observado se este percentual é maior ou não aos índices de evasão do curso, pois se forem equivalentes aos índices de evasão, o problema requer outras formas de tratamento, mas caso seja superior à evasão média do curso, é preciso uma investigação específica a esta disciplina.

Com forma de possibilitar a exame dos dados sob diferentes perspectivas, eles foram acumulados em diferentes filtros, por turma, pode ser possível examinar especificamente os dados de uma única turma de acordo com sua data de ingresso. E, também, por período letivo, ou seja, uma análise que de todas as disciplinas ofertadas em um período letivo, independente da turma.

Por fim, o acúmulo do curso como um todo (um total de 138 disciplinas ofertadas durante o período de análise) é quantificado e apresentado, totalizando 3538 casos de matrículas. A Tabela 2, traz o levantamento de todo o curso e a Tabela 3 apresenta o mesmo levantamento considerando o sistema de cotas. Reitera-se que as 3538 matrículas não correspondem à quantidade de alunos, mas à quantidade de matrículas existentes, a condição em que um aluno se matricula em uma disciplina, e um aluno pode ter 1 até 6 matrículas em um semestre letivo A retenção absoluta alcançada pelo curso foi de 33,01\% e a líquida de $17,72 \%$, esta discrepância não invalida nenhum dos dois valores, apenas possibilita análises e proposições diferenciadas. Existir uma retenção 
líquida não muda o fato de ter ocorrido 33,01\% (taxa absoluta) de reprovação no curso, mas demonstra que é elevado o número de alunos que desistem e simplesmente abandonam a disciplina $(20,02 \%)$, casos estes que devem ser gerados por um grupo específicos de motivos, ligado, tanto à evasão quanto à retenção. Já a retenção líquida representa alunos que frequentaram as disciplinas, buscaram a aprovação e mesmo assim resultando em insucesso, o que já pode representar motivos ligados a dificuldades de aprendizagem ou ao uso de metodologias e/ou instrumentos de avaliação de aprendizagem não adequados.

Tabela 2. Retenção - Curso Sistemas de Informação

\begin{tabular}{lccc}
\hline \multicolumn{1}{c}{ Item } & Quantidade & Média & Proporção \\
\hline \hline Matriculados & 3538,00 & 26,49 & - \\
\hline \hline Quantidade Frequentadores & 2867,00 & 21,50 & $81,03 \%$ \\
\hline \hline Aprovados & 2370,00 & 18,04 & $66,99 \%$ \\
\hline \hline Retidos & 1168,00 & 8,77 & $33,01 \%$ \\
\hline \hline Repronção Líquida & 508,00 & 3,85 & $17,72 \%$ \\
\hline \hline Reprovados por Faltas & 716,00 & 5,75 & $24,97 \%$ \\
\hline Reprovados por Nota & 245,00 & 2,03 & $8,55 \%$ \\
\hline \hline Exame Final & 354,00 & 2,70 & $12,35 \%$ \\
\hline Aprovados Direto & 247,00 & 2,92 & $8,62 \%$ \\
\hline \hline Aprovados Exame Final & 2221,00 & 16,91 & $77,47 \%$ \\
\hline \hline Reprovados Exame Final & 149,00 & 1,45 & $5,20 \%$ \\
\hline \hline Média de Notas Geral & 109,00 & 1,08 & $3,80 \%$ \\
\hline \hline Média de NotasFrequentadores & - & 6,23 & - \\
\hline \hline Cancelado & 90,00 & 3,03 & $3,14 \%$ \\
\hline \hline Média Frequência - Geral & 574,00 & 9,51 & $20,02 \%$ \\
\hline Média Frequência - Frequentes & - & $80 \%$ & - \\
\hline \hline
\end{tabular}

Fonte: Elaborada pelos autores.

Diferente das tabelas anteriores, esta perspectiva demonstrada na 
Tabela 2 traz as colunas Médias e Proporção. A coluna média estabelece uma média baseando-se no total de matrículas e na quantidade de disciplinas oferecidas para esta turma, por exemplo, houve 2370 aprovados com a média de 18 aprovados por disciplina ofertada, o que corresponde a $66,99 \%$, como traz o dado da coluna Proporção que é apenas uma mostra percentual dos dados da coluna Quantidade, demonstrando a proporção sob o número de matriculados. Inicialmente a contabilização da média era determinar a previsão de ocorrência de cada fato para cada disciplina, por exemplo, tendo-se a média de 2,88 de retenção líquida por disciplina para esta turma, poderia esperar que para cada disciplina ofertada tivesse entre 2 e 3 alunos retidos. Porém, tal observação é errônea devido à grande variação desses valores a cada disciplina, que depende da fase de oferta da disciplina (há maior reprovação nos primeiros semestres) e ao tipo da disciplina, como por exemplo, enquanto a disciplina de Cálculo que apresentou um total de 44 retidos (considerando as três ofertas) a disciplina de Governança de Tecnologia da Informação apresentou apenas 3 retidos (considerando as três ofertas).

Não é possível afirmar que a realidade de abandono de disciplina no percentual aqui encontrado é uma característica do curso de Sistemas de Informação, nenhum dos trabalhos correlatos traz esta perspectiva, mas em Lobo (2012), é destacado que a taxa de evasão em cursos de ciências exatas no Brasil é de $28 \%$, considerando esse percentual pode-se aferir que a evasão justifica essa alta retenção absoluta e a disparidade entre a retenção líquida.

A universidade em que o estudo foi realizado possui políticas afirmativas para ingresso, oferecendo cotas proporcionais a negros, com o Programa de Integração e Inclusão Étnico-Racial - PIIER e alunos provenientes de escolas públicas. Com o objetivo de avaliar esta política, foi realizada uma análise da retenção sob a perspectiva da forma de ingresso. Assim, todos os dados podem ser filtrados para visualizar as perspectivas gerais, de ampla concorrência, de cotas raciais, de cotas de origem da escola pública e cotas como um todo.

Na Tabela 3, os dados são especialmente preparados para critérios de comparação entre o ingresso por cota e ampla concorrência, nela não são trazidos dados quantificados como nas tabelas anteriores, mas todos valores representam percentuais sobre o total de matriculados de cada forma de ingresso, o objetivo desta apresentação, é poder comparar o percentual de cada forma de ingresso, com o percentual médio obtido pelo curso para cada um dos itens analisados. Desta maneira, cada item é comparado a média do curso e é atribuído a cor azul para valores positivos em relação à média do curso e a cor vermelha para valores negativos em relação à média do curso. $\mathrm{A}$ 
categorização de negativo e positivo depende do item analisado, por exemplo, a taxa de aprovação é positiva quando ela é maior que a média do curso e a taxa de retenção é positiva quando ela é menor que a média do curso.

\section{Tabela 3. Retenção - Proporção por Cotas}

\begin{tabular}{c|c|c|c|c}
\hline Itens & $\begin{array}{c}\text { Não } \\
\text { Cotista }\end{array}$ & $\begin{array}{c}\text { Escola } \\
\text { Pública }\end{array}$ & PIIER & $\begin{array}{c}\text { Cotas } \\
\text { (EP+PIIER) }\end{array}$ \\
\hline $\begin{array}{c}\text { Quantidade } \\
\text { Frequentadores }\end{array}$ & $80 \%$ & $83 \%$ & $83 \%$ & $83 \%$ \\
\hline Aprovados & $64 \%$ & $71 \%$ & $69 \%$ & $70 \%$ \\
\hline Retidos & $36 \%$ & $29 \%$ & $31 \%$ & $30 \%$ \\
\hline Retenção Líquida & $20 \%$ & $14 \%$ & $17 \%$ & $15 \%$ \\
\hline $\begin{array}{c}\text { Reprovados por } \\
\text { Faltas }\end{array}$ & $28 \%$ & $21 \%$ & $23 \%$ & $22 \%$ \\
\hline $\begin{array}{c}\text { Reprovados } \\
\text { Direto por Nota }\end{array}$ & $10 \%$ & $7 \%$ & $7 \%$ & $7 \%$ \\
\hline $\begin{array}{c}\text { Reprovados por } \\
\text { Nota }\end{array}$ & $14 \%$ & $10 \%$ & $11 \%$ & $10 \%$ \\
\hline $\begin{array}{c}\text { Exame Final } \\
\text { Aprovados Direto }\end{array}$ & $7 \% \%$ & $81 \%$ & $77 \%$ & $80 \%$ \\
\hline $\begin{array}{c}\text { Aprovados } \\
\text { Exame Final }\end{array}$ & $6 \%$ & $5 \%$ & $6 \%$ & $5 \%$ \\
\hline $\begin{array}{c}\text { Reprovados } \\
\text { Exame Final }\end{array}$ & $4 \%$ & $3 \%$ & $4 \%$ & $3 \%$ \\
\hline $\begin{array}{c}\text { Cancelado } \\
\text { Abandono }\end{array}$ & $22 \%$ & $17 \%$ & $18 \%$ & $17 \%$ \\
\hline
\end{tabular}

Fonte: Elaborada pelos autores.

Os alunos provenientes do ingresso por meio da cota PIIER ou escola pública demonstraram ter vantagem sobre os alunos não cotistas que acumularam os piores resultados no curso em vários aspectos, no entanto, a variação é apenas de 1 a 7 pontos percentuais de acordo com cada item a ser analisado. Diversos estudos destacam a importância de se avaliar o impacto do sistema de cotas no ensino superior tanto sob o aspecto da evasão, quanto do desempenho acadêmico. Em Queiroz (2015) é relatado que é nula a diferença de desempenho acadêmico entre cotistas e ampla concorrência dependendo 
do sistema seletivo para ingresso, através do processo próprio da instituição há essa condição de nulidade, e somente através do ingresso por meio do SISU que alunos da ampla concorrência tem vantagem de desempenho sob os cotistas, os autores atribuem o fato ao SISU por proporcionar ingresso mais amplo a todas as regiões do país e assim uma maior concorrência. Ainda, no estudo de Queiroz (2015), destaca-se que em curso da área de ciências exatas (independente da forma de ingresso) a diferença de desempenho é nula, o que condiz com os resultados aqui alcançados.

Em Cavalcanti (2019), é identificado que ao considerar toda instituição universitária, os alunos não cotistas possuem um melhor desempenho acadêmico, no entanto, ao considerar as áreas do conhecimento, essa vantagem só se aplica aos cursos de saúde e se anulam nas demais áreas do conhecimento. É importante ressaltar que, nos dois estudos, os autores utilizaram como parâmetro o desempenho acadêmico em relação a notas obtidas e, no presente estudo, é utilizado o critério de reprovação ou aprovação.

Dessa maneira, os resultados aqui encontrados são positivos em relação a instituição, especificamente relacionados a este curso. Como relata Cavalcanti (2019), sobre o conceito de incompatibilidade de (SANDER, 2004; SOWELL, 2004):

\footnotetext{
De acordo com a hipótese de incompatibilidade, a inserção dos estudantes cotistas em um mesmo ambiente de ensino com alunos ingressantes pelo sistema de ampla concorrência, oriundos de estruturas de ensino normalmente de melhor qualidade, pode ocasionar diferenciais de desempenho acadêmico, com aumento nas taxas de reprovação e evasão dos estudantes cotistas. Se esta hipótese se confirma, o processo de formação e acumulação de capital humano dos grupos minoritários não se completaria, perpetuando a situação de desvantagem em termos de produtividade e inserção no mercado de trabalho. Dessa forma, a política de cotas não estaria sendo eficaz. (CAVALCANTI, 2019, p. 307)
}

Assim, quando os resultados deste trabalho demonstram que não há perda de desempenho em relação aos alunos cotistas e não cotistas, auxiliam a validar a eficácia e permanência da metodologia de ingresso por cotas na instituição. Obviamente somente uma análise de toda instituição pode confirmar essa tendência. Talvez, seja ainda conveniente, uma análise de consulta a estes alunos com o objetivo de identificar as características no perfil de cada 
forma de ingresso, verificando como isso tem impactado sobre estes resultados.

Com o objetivo evidenciar possíveis particularidades nos componentes curriculares do curso, foram relacionadas as disciplinas com maior e menor índice de retenção, tanto absoluta quanto líquida. A Tabela 4 apresenta as 10 disciplinas com maior retenção absoluta.

Tabela 4. Maiores índices de Retenção Absoluta

\begin{tabular}{clcc}
\hline \hline ORDEM & \multicolumn{1}{c}{ NOME DISCIPLINA } & $\begin{array}{c}\text { Ret. } \\
\text { ABSOLUTA }\end{array}$ & $\begin{array}{c}\text { Ret. } \\
\text { LIQUIDA }\end{array}$ \\
\hline \hline 1 & ALGORITMO I & $61 \%$ & $47 \%$ \\
\hline \hline 2 & CÁLCULO & $57 \%$ & $31 \%$ \\
\hline \hline 3 & GEOMETRIA ANALITICA & $52 \%$ & $33 \%$ \\
\hline \hline 5 & PROBABILIDADE E ESTATISTICA & $49 \%$ & $27 \%$ \\
\hline \hline 6 & PROGRAMAÇÃO ORIENTADA A OBJETOS & $46 \%$ & $26 \%$ \\
\hline \hline 7 & TCC II & $46 \%$ & $37 \%$ \\
\hline \hline 9 & TEORIA GERAL DA ADMINISTRAÇÃO & $45 \%$ & $11 \%$ \\
\hline \hline 10 & PRODUÇÃO DE TEXTO E LEITURA & $42 \%$ & $9 \%$ \\
\hline \hline
\end{tabular}

Fonte: Elaborada pelos autores.

A Tabela 4, está ordenada pela retenção absoluta, e exibe a retenção líquida somente para critério de análise, de maneira que podemos observar como a ordem se alteraria ao considerar a retenção líquida, essas diferenciações podem demonstrar uma característica peculiar de cada disciplina. A disciplina de Teoria Geral da Administração, por exemplo, figura-se entre as disciplinas com maior retenção absoluta, mas possui somente $11 \%$ de retenção líquida (média entre as três vezes que a disciplina foi ofertada), trata-se de uma disciplina da área de administração dentro de um curso de tecnologia, sobre essa temática Sampaio (2012) identifica em seu estudo que os docentes têm encontrado dificuldades e ministrar disciplinas de gestão em cursos de tecnologia e apresenta as seguintes justificativas para este fato:

I - Menor motivação dos discentes para cursar disciplinas que envolvam gestão face a concorrência com as disciplinas de caráter mais técnico: pelo fato das disciplinas técnicas, como 
programação, análise, dentre outras, permitirem resultados práticos para o alunado, existe a tendência de maior atenção do mesmo para estas disciplinas, de caráter técnico, nos cursos da área de computação; II - Foco tradicionalmente teórico relacionado às disciplinas de gestão; III - Dificuldade na vinculação entre a formação e a prática profissional do egresso na área de gestão. (SAMPAIO, 2012, p. 105).

Considerando que esta disciplina é ofertada no segundo semestre do curso, onde há a expectativa por parte dos alunos em cursarem disciplinas técnicos e práticas, momento em que são apresentadas as diversas disciplinas base como português, metodologia, matemática e teoria geral da administração, pode-se evidenciar a percepção de Sampaio, e identificar que há uma frustração, desânimo e abandono destas disciplinas, mas não há de fato uma dificuldade em sua compreensão, uma vez, que a retenção líquida é muito inferior.

Pode ser observado nessas disciplinas dispostas da Tabela 4, que com a exceção de TCC II (ofertada no 8 o semestre), todas as demais são ofertadas do $2 \circ$ ao 4 을 semestre, sendo 3 delas somente do segundo semestre. Isso pode ser observado sob duas óticas, primeiro em relação a evasão, pois são nos semestres iniciais que apresentam os maiores índices de evasão e a partir do momento que se avança pelas fases do curso a evasão tende a diminuir e a retenção absoluta também. Um outro aspecto a ser observado é em relação a retenção dos alunos com menos perspectiva e maturidade no curso, o que afeta a retenção líquida também, pode-se observar que a disciplina com maior retenção é Algoritmo I, mas a disciplina com a menor retenção líquida do curso é de Algoritmo II, com $0 \%$ de retenção líquida (considerando três ofertas da disciplina), sendo ela uma disciplina subsequente ela possui Algoritmo I como pré-requisito para sua matrícula, aqueles alunos com dificuldades ou desmotivação em lógica de programação prevista em seu conteúdo ficam barrados pela regra do pré-requisito, e somente aqueles que obtiveram êxito cursam a subsequente (algoritmo II), são alunos que não apresentaram dificuldades nesse tipo de conteúdo que é base para o curso e assim obtém-se o êxito.

Posterirormente às disciplinas de Algoritmos 1 e 2, há um encadeamento de mais 4 disciplinas com requisitos (estrutura de dados I, estrutura de dados II, programação orientada a objetos e Desenvolvimento Web), o que demonstra a gravidade do problema de alta retenção nesta disciplina, pois desencadeia uma sequência de atrasos para o aluno no decorrer do curso, uma única reprovação pode atrasar a diplomação em até dois anos, a 
depender do horário acadêmico. A estas dificuldades pode-se adicionar que a retenção em si gera mais retenção, pois pode ocasionar turmas com grande número de alunos e elevada heterogeneidade de características cognitivas e ritmos de aprendizagem.

Ao considerar a retenção líquida, há algumas variações entre as disciplinas com pior desempenho, como pode ser visto na Tabela 5. Nessa perspectiva, não há mais as disciplinas de Teoria Geral da Administração e nem Produção de Texto e Leitura, ambas com as mesmas características, alta retenção absoluta (45\% e $42 \%$ respectivamente) e baixa retenção líquida ( $11 \%$ e $9 \%$ respectivamente), o que demonstra que não há demasiada dificuldade aqui no aprendizado, mas sim abandono da disciplina, o que pode inferir falta de maturidade acadêmica para associar tais conteúdos a formação prática da carreira.

Conforme já esperado, devido a todas as referências apontarem para disciplinas de programação como as que detêm os maiores taxas de reprovações, o resultado confirmou esta premissa, apresentando 4 disciplinas de programação entre as que apresentam maior retenção líquida, bem como, as disciplinas de matemática figuram-se como gargalos de retenção nos cursos de engenharia e das áreas de tecnologia (Sistemas de Informação, Ciência da Computação, Engenharia da Computação, entre outros cursos), no levantamento realizado 3 disciplinas ligadas à matemática estão dentre as disciplinas com maiores índices de retenção líquida, estas características podem estar ligadas a complexidade ofertada por estas disciplinas ou a deficiência proveniente do ensino médio, como Giraffa (2013) já destacou em seu trabalho a deficiência na formação básica, como no domínio da parte escrita da língua materna, interpretação de texto, hábitos de estudos e pesquisa e, nos conteúdos de matemática.

Tabela 5. Maiores índices de Retenção Líquida

\begin{tabular}{clcr}
\hline ORDEM & NOME DISCIPLINA & $\begin{array}{c}\text { Ret. } \\
\text { LÍQUIDA }\end{array}$ & $\begin{array}{r}\text { Ret. } \\
\text { ABSOLUTA }\end{array}$ \\
\hline \hline 1 & ALGORITMO I & $47 \%$ & $61 \%$ \\
\hline 2 & TCC II & $45 \%$ & $45 \%$ \\
\hline \hline 3 & ENGENHARIA DE SOFTWARE & $37 \%$ & $46 \%$ \\
\hline \hline 4 & GEOMETRIA ANALITICA & $33 \%$ & $52 \%$ \\
\hline \hline 5 & CÁLCULO & $31 \%$ & $57 \%$ \\
\hline \hline
\end{tabular}




\begin{tabular}{clcc}
\hline \hline 6 & PROBABILIDADE E ESTATISTICA & $27 \%$ & $49 \%$ \\
\hline \hline 7 & BANCO DE DADOS & $27 \%$ & $40 \%$ \\
\hline \hline 8 & PROGRAMAÇÃO ORIENTADA A OBJETOS & $26 \%$ & $46 \%$ \\
\hline \hline 10 & ESTRUTURAS DE DADOS II & $23 \%$ & $32 \%$ \\
\hline \hline
\end{tabular}

Fonte: Elaborada pelos autores.

Nascimento (2018) destaca que, o problema relacionado à disciplina de cálculo surge na educação básica no momento da ruptura da matemática básica, quando o aluno vê sua aplicabilidade no dia a dia, assim, entra na matemática com variáveis e teoremas complexos que ele não consegue mais vincular aos problemas do cotidiano. Tal grave e problemática é a reprovação nas disciplinas de cálculo no ensino superior, que Oliveira (2012) destaca a seguinte perspectiva:

Em alguma medida, a relação entre um bom professor/um bom curso de Cálculo se dá na mesma proporção do índice de reprovação dos estudantes. A reprovação ainda está muito mais associada à qualidade do curso do que à inadequação do mesmo ao grupo de estudantes ou ao momento sociocultural. Assim, um curso considerado bom é sinônimo de forte, o que implica em significativo número de reprovados. (OLIVEIRA, 2012, p. 126).

Oliveira (2012), destaca ainda que, medidas adotadas atualmente como aumento de carga horária, revisões, ampliação do número de exercícios ou disciplinas de nivelamento, quando colocadas em perspectiva histórica, revelam-se como paliativos com sucesso relativamente pontual, não alterando a cultura de reprovação estabelecida.

Outro fator notável no levantamento das disciplinas com maior retenção, são as disciplinas de Trabalho de conclusão de Curso (TCC) I e II, evidenciando as dificuldades dos acadêmicos em realizar pesquisa científica. Tal fato demonstra dois agravantes na formação superior, primeiro que esta dificuldade na disciplina de TCCI atrasa a diplomação de alunos considerando que são subsequentes e a primeira é pré-requisito da segunda, não sendo possível cursar as duas ao mesmo tempo, a reprovação em TCC I já provoca diretamente seis meses de atraso, mesmo que ele já tenha completado todos os demais créditos, o segundo agravante é que o curso está formando profissionais sem a familiaridade com a pesquisa científica ou escrita acadêmica. 
Complementa-se aqui, o fato de não haver controle de frequência na disciplina de TCC II, devido a isso é idêntico o índice de retenção absoluta e líquida (45\%), não dá para saber aqui se estes alunos tentaram de fato realizar sua pesquisa, realizando o atendimento com os professores orientadores, ou simplesmente abandonaram a disciplina desistindo da pesquisa logo no início do semestre. A abordagem de retenção líquida tem esse objetivo, de demonstrar mesmo sem realizar consultas e entrevistas a professores e alunos, da maneira mais completa possível o que ocorreu na disciplina durante a oferta no semestre letivo, ou no decorrer do curso.

Por fim, chama-se a atenção para a Tabela 8, para o fato que 3 dentre as 10 com maior retenção, pertencerem a 4a fase do curso. Isso pode inferir um alto nível de dificuldade encontradas nas disciplinas ofertadas nessa fase. Ao planejar a matriz curricular, além da ordem lógica do conteúdo é também previsto pelos docentes do curso balancear o grau de dificuldade enfrentado em cada semestre, procurando não alocar muitas disciplinas complexas no mesmo semestre. No entanto, esta análise pode demonstrar se o planejamento desse balanceamento alcançou o objetivo, aparentemente, para este curso não.

Ao explicitar as disciplinas com menores índices de retenção líquida, o resultado é dentro do esperado, com exceção da disciplina de Algoritmo II, todas as demais são correspondentes do 6a até a 8a fase do curso, momento em que se reduz drasticamente a evasão e as reprovações. Pode-se atribuir a isso a maturidade obtida e ao fato de que os alunos com maiores dificuldades ainda se encontram retidos nas primeiras fases do curso. 0 gráfico 1 , apresenta a ocorrência da retenção de acordo com as fases do curso.

É evidenciado no gráfico 1 que a retenção líquida sempre se mantém inferior a retenção absoluta, mas a diferença diminui consideravelmente a partir da 5 o fase do curso por motivos aqui já tratados, como a menor taxa de evasão e a maturidade acadêmica. Conforme observado nas disciplinas com maior retenção, elas estão relacionadas entre $2^{a}$ e a $4 \underline{a}$ fase, intervalo onde é evidenciado que há maiores taxas de retenção. Mesmo havendo a queda da 5a fase em diante é apresentado um aumento na 8a fase do curso, provocado pelo impacto da disciplina de TCCII. 


\section{Gráfico 1. Retenção por semestre.}

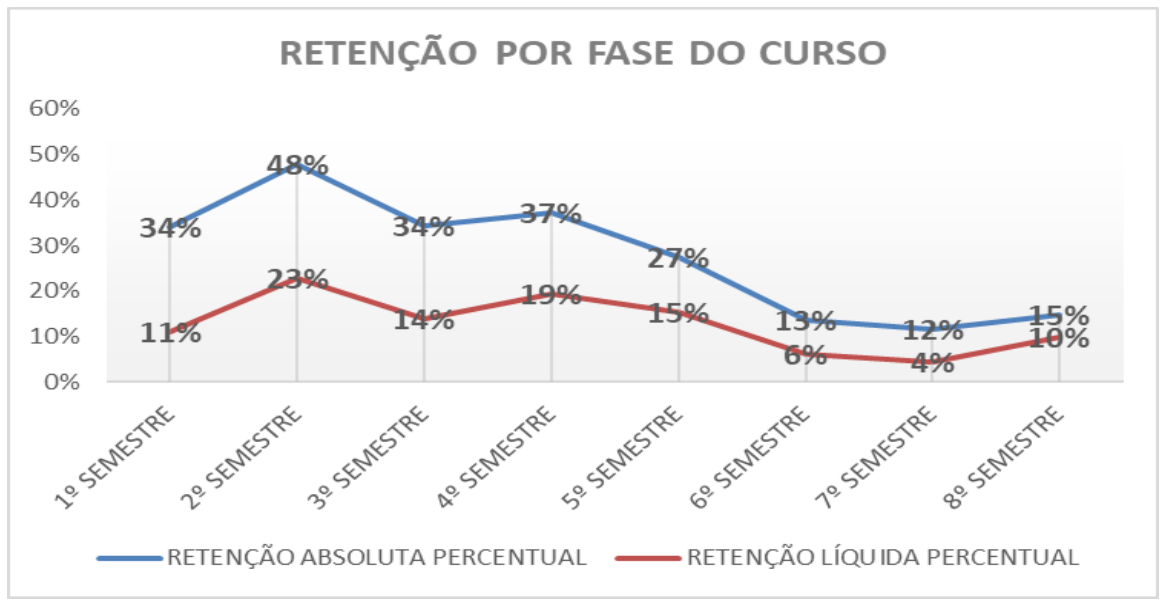

Fonte: Dados de pesquisa documental dos autores.

Estas características podem ser associadas às motivações pela retenção, o abandono das disciplinas (baixa frequência) nas séries iniciais pode representar as dificuldades de adaptação dos acadêmicos à nova modalidade de ensino. Confirma ainda a alta evasão nas fases iniciais, desse modo a evasão influencia mais sobre a retenção nos semestres iniciais, já com o avanço do curso, a retenção ocorrendo por desempenho (notas), fator que já caracteriza problemas de aprendizagem, neste caso a retenção pode ter maior influência sobre a evasão.

\section{Considerações Finais}

Ações com o objetivo de minimizar os problemas acadêmicos, são fundamentais para os gestores universitários ao definir questões de viabilidade na oferta de cursos superiores, principalmente em campus universitário que enfrente problemas de baixa procura em seus cursos e, muito importante em cursos da área de ciências exatas e tecnologia onde a evasão vem se apresentado de forma acentuada e a retenção é tradicionalmente alta nestes cursos.

Conforme observado em todos os trabalhos correlatos e apontado em MEC (1997), o combate ao fenômeno da retenção ou evasão tem, em seu primeiro momento (como uma ação essencial), a necessidade de se realizar um levantamento quantitativo, como um diagnóstico da situação que se encontra um curso ou uma instituição. Nesse sentido, esse levantamento e a compilação 
de dados são úteis para instituição e para os pesquisadores sobre o tema, ainda que o diagnóstico seja predominantemente quantitativo não dimensionando qualitativamente. A partir da comprovação ou refutação dos fatos e hipóteses realizados pelos dados quantitativos aqui levantados, pode-se tornar o levantamento qualitativo mais eficaz. Busca-se agora um levantamento sobre a percepção dos docentes que trará uma contribuição mais fidedigna, uma vez que, agora o docente tem acesso aos dados concretos sobre a retenção no curso e em suas disciplinas, podendo se basear nesses dados para refletir suas práticas docentes e sobre as observações feitas dos alunos ao longo dos anos.

Os resultados demonstram que quanto maior for o detalhamento dos casos de retenção, há uma melhor possibilidade de compreensão do fenômeno. Assim como a evasão, as causas do problema estudado possuem diversos fatores influentes, ao se obter a taxa de retenção de um curso como um todo, dificilmente é possível identificar as suas causas, ou utilizar esta informação para planejar ações de mitigação. Dessa maneira, este estudo preenche lacunas deixadas por outras metodologias de levantamento realizadas em estudos anteriores, pois o detalhamento oferecido ao tratar a retenção individualmente em cada disciplina possibilita diversas combinações de pontos de vistas e análise. Sendo a retenção abordada por vários autores como a permanência prolongada do acadêmico no curso antes de concluir a graduação, é inerente que a origem deste problema seja estudada nas disciplinas, pois é a retenção nas disciplinas que provoca a permanência prolongada no curso. Em cursos como Sistemas de Informação o currículo propõe disciplinas de áreas distintas e pode exigir diferentes aspectos de aprendizagem como disciplinas de administração, matemática, ciências sociais, programação, tecnológica, computação aplicada, dificilmente um fator oferecerá influência sobre a retenção em todas elas, nestas condições a metodologia se adequa, pois, possibilita tratar as particularidades das ocorrências em cada um desses grupos de disciplinas.

As tendências identificadas demonstram a alta incidência de abandono nas disciplinas iniciais, em alguns casos com incipiente reprovação por nota (líquida), situação a qual conclui-se que a dificuldade de aprendizagem não é o problema maior. Mas, há também casos em que há a retenção por falta e por nota insuficiente, mesmo em disciplinas iniciais, casos das disciplinas de matemática e programação, nas quais se evidenciam as deficiências de aprendizagens. Também foi observado a heterogeneidade nas matrículas realizadas em disciplinas, situações em que alunos de diferentes fases estavam presentes na mesma disciplina. Esta situação é um reflexo do sistema de créditos, onde o aluno pode se matricular em quaisquer disciplinas desde que

Rev. Fac. Educ. (Univ. do Estado de Mato Grosso), Vol. 34, Ano 19, № 2, p. 15-38, jul/dez., 2020 (Epub Ahead of Print 20 set., 2020) 
não haja pré-requisitos, dessa maneira um aluno que é reprovado, acaba por ter horários livres devido ao choque no horário, e se matricula em disciplinas disponíveis nos horários vagos, mesmo que elas sejam de fases avançadas. Tal possibilidade flexibiliza o currículo, mas é uma situação a ser tratada, a ausência de pré-requisito não anula o fato que certa maturidade e habilidades técnicas sejam exigidas em disciplinas de fases mais avançadas no curso.

É fato que, uma análise nos diversos cursos da instituição traga informações mais enriquecedoras e passíveis de discussão, bem como, o estabelecimento de tendências. Para tanto, é necessário que a metodologia seja adotada e utilizada em todos os levantamentos, para que existam parâmetros de comparação e as informações possam ser acumuladas e filtradas para possibilitar diferentes visualizações, como reprovação por áreas de conhecimento, turnos, sexo, idade, dentre outras informações relevantes para a análise.

\section{Referências}

ASSIS, C. F. Estudo dos fatores que influenciam a evasão dos alunos nos Cursos Superiores de Tecnologia de uma Instituição de Ensino Superior Privada. Dissertação Mestrado Profissional em Administração Fundação Cultural Dr. Pedro Leopoldo, Pedro Leopoldo, 2013.

BOSSE,Y.;e GEROSA,A.Reprovações e Trancamentos nas Disciplinas de Introdução à Programação da Universidade de São Paulo:Um Estudo Preliminar. XXIII WEI. PE,Jul. 2015.

CAMPELLO, A. V. C.; LINS L. N. Metodologia De Análise E Tratamento Da Evasão E Retenção Em Cursos De Graduação De Instituições Federais De Ensino Superior. XXVIII Encontro Nacional de Engenharia De Produção. Rio de Janeiro, RJ, Brasil, outubro de 2008.

CAVALCANTI, I. T. N. et al. Desempenho acadêmico e o sistema de cotas no ensino superior: evidência empírica com dados da Universidade Federal da Bahia. Avaliação (Campinas), Sorocaba, v. 24, n. 1, p. 305-327, May 2019.

CESARINO, M. A.N. et al. Retenção de Alunos Por Infrequência, Aproveitamento E Trancamento de Matrícula no Curso de Graduação de Biblioteconomia da Universidade Federal de Minas Gerais. Revista da Escola de Biblioteconomia da UFMG, Belo Horizonte, V. 16, N. 2, P. 159-190, Set. 1987.

COMISSÃO ESPECIAL DE ESTUDOS SOBRE EVASÃO - CEESE (MEC/ANDIFES / ABRUEM/SESU). Diplomação, Retenção E Evasão Nos Cursos De Graduação Em Instituições De Ensino Superior Públicas. Brasília, 1996. 
FERREIRA, M. Determinantes do Rendimento Académico no Ensino Superior. Revista Internacional d' Humanitats 15 jan-abr 2009.

GIRAFFA, L.M.M.; MORA, M.C. Evasão na disciplina de algoritmo e programação: um estudo a partir de fatores intervenientes na perspectiva do aluno. III CLAES . Mexico.2013.

LAMERS, J. M. S. et al. Retenção e Evasão no Ensino Superior Público: Estudo de Caso em um Curso Noturno de Odontologia. Educ. rev., Belo Horizonte, v. 33, e154730, 2017.

LAUTERT, L. V. dos S.; ROLIM, M.; LODER, L. L. Investigando processos de retenção no âmbito de um curso de engenharia elétrica. In: COBENGE, 39., 2011.

LOBO, R. L. et al. A Evasão No Ensino Superior Brasileiro. Cadernos de Pesquisa, V. 37, N. 132, P. 641-659, Set./Dez. 2007.

MEC - Ministério da Educação e Cultura "Diplomação, Retenção e Evasão nos cursos de Graduação em Instituições de Ensino Superior Públicas". Brasília. 1997.

NASCIMENTO, K. S. Análise do Índice de Reprovação e Evasão na Disciplina de Cálculo Diferencial e Integral I da UFCG -Cuité. Anais III CONAPESC, V. 1, 2018.

OLIVEIRA, M. C. A., RAAD, M. R. A existência de uma cultura escolar de reprovação no ensino de Cálculo. BOLETIM GEPEM | № 61 - JUL. / DEZ. 2012 | 125-137.

PARKER, J.D.A. et al. Emotional intelligence and academic success examining the transition from high school to university. Personality and Individual Differences, 36, 163-172. 2004.

PEREIRA A. S. et al. Principais Características dos Alunos Retidos dos Cursos de Graduação Presencial Da Universidade Federal do Espírito Santo. Revista GUAL, Florianópolis, v. 9, n. 2, p. 238-259, maio 2016.

QUEIROZ,L. S. et al. A lei de cotas na perspectiva do desempenho acadêmico na Universidade Federal de Uberlândia. Rev. Bras. Estud. Ped., Brasília , v. 96, n. 243, p. 299-320, Aug. 2015.

RIOS, J. R. T.; SANTOS, A. P. dos; NASCIMENTO, C. Evasão e retenção no ciclo básico dos cursos de engenharia da Escola de Minas da UFOP. In: COBENGE, 29, 2001, Porto Alegre. 
RISSI, M. C.; MARCONDES, M. A. S. (orgs). Estudo sobre a reprovação e retenção nos cursos de graduação - 2009. Relatório. Londrina: UEL, 2011.

RISSI, M. C.; MARCONDES, M. S. Reflexão sobre a reprovação, retenção e evasão na UEL: retenção 2010, reprovação 2010 a 2012, evasão 2003 a 2012 nos cursos de graduação. 2013.

SAMPAIO, A. L.; BANDEIRA, W. A. Avaliação de Práticas Pedagógicas Inovadoras em Curso de Graduação em Sistemas de Informação. REICE. Revista Iberoamericana sobre Calidad, Eficacia y Cambio en Educación, vol. 11, núm. 1, 2013, pp. 104-121.

SANDER, R. H. A systemic analysis of affirmative action in american law schools. Stanford Law Review, Stanford, v.57, n.367, p.57-367, nov.2004.

SILVA F. et al. A evasão no ensino superior brasileiro. Cad. Pesqui., São Paulo, v.37, n.132, p.641-659, 2007.

SOWELL, T. Affirmative action around the world: an empirical study. New Haven: Yale University Press, 2004.

UFES. Universidade Federal do Espírito Santo. 2013. Disponível em: http:// www. graduacao.ufes.br/sites/graduacao.ufes.br/files/field/anexo/sistemas\%20de\%20informacao.pdf

VANZ, S. A. et al. Evasão e retenção no curso de Biblioteconomia da UFRGS. Avaliação (Campinas), Sorocaba, v. 21, n. 2, p. 541-568, July 2016.

YAMAGUCHI, K. L.; SILVA, J. S. Avaliação das Causas de Retenção em Química Geral na Universidade Federal Do Amazonas. Quím. Nova, São Paulo, v. 42, n.3, p.346-354, mar.2019. 